\title{
AVALIAÇÃO DA PERCEPÇÃO ESPACIAL DE USUÁRIOS DE PÁTIOS EM ESCOLAS DE ENSINO FUNDAMENTAL PÚBLICO EM PALMITINHO-RS
}

\author{
EVALUATION OF SPATIAL-PERCEPTION OF PATIENT USERS IN \\ PUBLIC FUNDAMENTAL EDUCATION SCHOOLS IN \\ PALMITINHO - RS
}

\author{
Gracielle Rodrigues da Fonseca Rech ${ }^{1}$, Esp. \\ Ângela do Valle ${ }^{2}$, Dra. \\ Bruna Cristina Lermen ${ }^{3}$, acad. \\ (1) Universidade Federal de Santa Catarina (UFSC) \\ Faculdade de Itapiranga (FAI) \\ e-mail: graciellerfrech@hotmail.com \\ (2) Universidade Federal de Santa Catarina (UFSC) \\ e-mail:angela.valle@ufsc.br \\ (3) Universidade Regional Integrada do Alto Uruguai e das Missões (URI) \\ e-mail: brunalermen@hotmail.com
}

Palavras-chave: Pátio escolar, percepção espacial, psicologia ambiental.

Em arquitetura, o processo de apropriação espacial é facilitado por espaços qualificados para os usuários, com aspectos ambientais que proporcionam bem-estar. Partindo do tema arquitetura de pátios escolares, a pesquisa teve por objetivo analisar o pátio de escolas de ensino fundamental, segundo o ponto de vista da criança estudante, usuária direta desse tipo de ambiente. $\mathrm{O}$ artigo apresenta a avaliação realizada em três instituições públicas de ensino fundamental localizadas no município de Palmitinho - Rio Grande do Sul, com ênfase em dois dos instrumentos realizados: mapa cognitivo e poema dos desejos. A participação dos usuários mostrou-se fundamental para a obtenção de espaços de qualidade.

Key words: Schoolyard, spatial perception, environmental psychology.

In architecture, the process of spatial appropriation is facilitated by spaces qualified for users, with environmental aspects that provide well-being. Starting from the theme of the architecture of schoolyards, the research had the objective of analyzing the courtyard of elementary schools, according to the point of view the of student, a direct user of this type of environment. The article presents the evaluation carried out in three public institutions of basic education located in the municipality of Palmitinho - Rio Grande do Sul, with emphasis on two of the instruments 
$16^{\circ}$ USIHC - Congresso Internacional de Ergonomia e Usabilidade de Interfaces Humano Computador

CINAHPA | 2017 - Congresso Internacional de Ambientes Hipermídia para Aprendizagem.

carried out: cognitive map and poem of desires. The participation of the users was fundamental for the obtaining of quality spaces.

\section{Introdução}

O presente artigo relata os resultados parciais da pesquisa desenvolvida sobre apropriação espacial em pátios escolares, tendo em vista que tais espaços muitas vezes são tratados como mero espaço que "sobrou" no terreno, inadequado para as atividades de recreação, exploração, convívio e socialização das crianças (AZEVEDO, RHEINGANTZ E TÂNGARI, 2002). Visando compreender como se dá a apropriação destes espaços, realizou-se um estudo de caso e levantamento a campo em três escolas de Ensino Fundamental das sete escolas identificadas em Palmitinho, pequeno munícipio localizado na região noroeste do estado gaúcho.

O enfoque no pátio escolar pode ser justificado pelo mesmo configurar-se como elemento importante na formação do ser humano. A harmonia entre o usuário e o ambiente é uma questão que deve ser relacionada, pois deve haver uma interação entre espaço físico, atividades pedagógicas e comportamento humano.

Assim, embora exerça uma importante função, que influencia todo o processo de desenvolvimento infantil, há poucas reflexões sobre a concepção de pátios escolares no Brasil, segundo Azevedo; Rheingantz; e Tângari (2011). "É comum, no processo projetual que a área destinada ao pátio seja tratada e concebida como mero espaço residual - "sobra" do terreno -, inadequado para as atividades de recreação, exploração, convívio e socialização das crianças" (AZEVEDO; RHEINGANTZ; TÂNGARI, 2011).

A partir destas abordagens, o estudo realizado tem como objetivo analisar a organização dos pátios das escolas, com ênfase no uso e na apropriação pelos usuários. Procurou-se investigar e observar quais aspectos dos pátios escolares interfere na apropriação espacial por parte dos estudantes. $\mathrm{O}$ foco da pesquisa está na observação e compreensão de como o usuário percebe e experimenta o ambiente, modificando-o ou não, aplicando técnicas e instrumentos de avaliação pós-ocupação para o desenvolvimento dessas análises.

Segundo Rheingantz et al (2009: 16), a Avaliação Pós-Ocupação (APO) é um processo interativo, sistematizado e rigoroso de avaliação do desempenho do ambiente construído, passado algum tempo de sua construção e ocupação. Os conceitos e técnicas adotados fazem parte de um escopo para se absorver e compreender como a comunidade e usuários percebem, observam e interagem com o ambiente. Os resultados da APO, conforme Tavares (2012),podem servir de subsídios para novos projetos similares, com a intenção de não possuírem os mesmos problemas já constatados, bem como para correção de projetos existentes. Assim, os procedimentos de análise do ambiente dos pátios escolares se dividiram em dois:

(a) Análise objetiva (aspectos físicos e morfológicos), onde se realizou o mapeamento dos locais e levantamento de dados, com o objetivo de analisar os espaços livres existentes nas edificações elencadas. Ressalta-se que devido aos projetos arquitetônicos não estarem disponíveis, tal procedimento foi realizado in loco, com auxílio de trenas.

(b) Análise subjetiva (aspectos subjetivos, simbólicos e culturais), na qual se analisa como se dá a ocupação das áreas livres, as atividades realizadas e o comportamento dos usuários, de acordo com suas vivências e experiências, havendo uma interação direta ou indireta entre o pesquisador e os usuários.

Tais análises são complementares entre si, e auxiliam na obtenção dos objetivos da pesquisa. Ressalta-se que o artigo desenvolve-se a partir da análise subjetiva realizada de modo a responder as seguintes inquietações motivadoras: Como o estudante vê e sente o espaço? Quais anseios os
Realização:

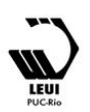




\section{$16^{\circ}$ \\ ERGODESIGN USIHC CINAHPA}

usuários apresentam sobre o mesmo? Desta forma, o artigo irá focalizar a construção e aplicação de apenas dois instrumentos pertencentes ao grupo de análise subjetiva - mapa cognitivo e poema dos desejos, devido à relação direta existente entre usuários e pesquisador nessas técnicas. No decorrer da transcrição do artigo, serão apresentadas as etapas desenvolvidas durante a realização da análise subjetiva, dando ênfase à metodologia aplicada para a realização de tal estudo, bem como a análise e síntese dos resultados obtidos a partir dos estudos de casos realizados nas três escolas públicas de ensino fundamental analisada.

\section{Fundamentação teórica}

A etimologia da palavra pátio - do latim: Pateo define como: estar aberto; exposto; estender-se; abrir-se; estar descoberto; manifestar-se; ser evidente. As palavras sugerem o conceito de relacionamento com o ambiente físico, a cultura, as pessoas, etc.

Apesar da importância do pátio em termos de dimensão $\left(\mathrm{m}^{2}\right)$ e como local de atividade e interação social, na maioria das escolas brasileiras, este espaço é omitido. Assim, os pátios escolares ainda são vistos apenas como um lugar onde as crianças podem ficar quando não estão desenvolvendo suas atividades em sala de aula, e por isso não seguem um projeto definido (Fedrizzi, 2002).

O ministério da Educação não estabelece critérios específicos para a construção dos pátios das escolas. Sua única recomendação é que a área livre da escola deva ocupar pelo menos $50 \%$ do terreno disponível (Brasil, 1998, 1993, 1985). Desta forma, não é suficiente julgar somente a metragem do terreno, também é preciso buscar a qualidade do espaço.

Outra característica que evidencia a noção do pátio escolar como sendo espaço residual é que as atividades diversas de apoio ao processo pedagógico, entre elas as lúdicas, encontram-se dispersas no programa de atividades pedagógicas. Entende-se que o "brincar" deve fazer parte do $16^{\circ}$ Ergodesign - Congresso Internacional de Ergonomia e Usabilidade de Interfaces Humano Tecnológica: Produto, Informações Ambientes Construídos e Transporte

$16^{\circ}$ USIHC - Congresso Internacional de Ergonomia e Usabilidade de Interfaces Humano Computador

CINAHPA | 2017 - Congresso Internacional de Ambientes Hipermídia para Aprendizagem. processo educativo. A atividade lúdica possibilita que a criança experimente, explore, desenvolva sua vivência com o mundo concreto e subjetivo. No entanto, os pátios e as áreas livres das escolas têm sido reduzidos ou até mesmo eliminados; e quando existem são geralmente pouco convidativos ou acumulam outras funções, como extensão do refeitório e área de circulação.

Nos locais e situações de brincadeira, a criança é agente de seu próprio desenvolvimento, na medida em que atua selecionando as suas atividades e objetos, seus lugares preferidos e seus colegas; por outro lado, ela também é influenciada pelo ambiente sócio físico em que se encontra, que pode facilitar e alterar seus comportamentos. A forma de a criança agir, por sua vez, também modifica o ambiente.

Segundo Gonçalves e Flores (2011), uma boa arquitetura de pátio escolar deve atender as necessidades das crianças de: (a) estabelecer o contato social para permitir o desenvolvimento das habilidades de comunicação que não são permitidas em sala de aula, como o diálogo espontâneo ou o namoro, (b) brincar e jogar, atividades lúdicas que podem acontecer de maneira espontânea, além de desenvolver a capacidade do trabalho em equipe; (c) desenvolver a motricidade e os sentidos, que são atividades que permitem à criança conhecer-se melhor e ter um controle maior sobre o seu corpo, aumentando a autoestima e a confiança em si mesma; (d) complementar as funções pedagógicas - quando o espaço livre serve como exemplo ou complemento do conteúdo trabalhado em sala de aula e (e) aproximar-se do meio ambiente e da própria educação ambiental.

Assim, como espaço de aprendizagem, o pátio ideal deve possuir mais que quadras e parques infantis, que são equipamentos encontrados em outras edificações não escolares. "Por outro lado, as decorações e murais comumente encontrados se mostram vazias perante o aluno sonhador e cheio de imaginação [...]" (MACEDO, 2011). Como conceito principal, o pátio precisa servir de local complementar ao aprendizado, procurando oferecer transição entre espaços abertos ao ar livre, e cobertos, oferecendo possibilidades diversas de
Realização:

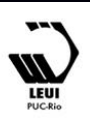




\section{$16^{\circ}$ \\ ERGODESIGN USIHC CINAHPA}

$16^{\circ}$ Ergodesign - Congresso Internacional de Ergonomia e Usabilidade de Interfaces Humano Tecnológica: Produto, Informações Ambientes Construídos e Transporte

$16^{\circ}$ USIHC - Congresso Internacional de Ergonomia e Usabilidade de Interfaces Humano Computador

CINAHPA | 2017 - Congresso Internacional de Ambientes Hipermídia para Aprendizagem. usos e apropriações.

Segundo Fedrizzi (1999), é necessário que o pátio da escola possua certos elementos e ofereça certas oportunidades e facilidades. Seriam eles: demonstrar cuidado, possibilitar a aprendizagem, dar oportunidades para brincar, oferecer segurança, possuir uma horta e pomar, ter a presença de vegetação, canchas para esportes, recantos ou esconderijos e abrigo contra intempéries.

Desta forma, conforme Azevedo (2002), a setorização e organização não podem ser muito rigorosas, permitindo que a criança possa controlar e se apropriar desse ambiente.

No que tange as técnicas subjetivas elencadas para o desenvolvimento da pesquisa, Rheingantz et al (2009) no livro Observando a Qualidade do Lugar, aborda o Mapa Cognitivo ou Mapa Mental elaborado por Kevin Lynch nos anos 50. Este instrumento consiste na elaboração de desenhos ou relatos de memórias representativas das ideias que uma pessoa tem de um determinado ambiente, podendo ser preenchido através de desenhos ou escrita.

Desta forma, o mapa cognitivo se torna uma importante ferramenta para entender quais espaços e características das escolas em análise expressam valores visuais para seus usuários, demonstrando bem a visão que as crianças e jovens têm da mesma.

No que tange ao Poema dos Desejos, este é um instrumento de pesquisa desenvolvida por Henry Sanoff (2001), na qual os usuários expressam graficamente, através de desenhos ou pela escrita suas relações emocionais e expectativas sobre determinado ambiente. Tem como ponto de partida a sentença previamente proposta "Eu gostaria que o (edifício/ ambiente)...", tratando-se de um instrumento não estruturado e de livre expressão (RHEINGANTZ et al., 2009).

\section{Instrumentos de análise}

Para que os objetivos inicialmente propostos na pesquisa mais abrangente sobre pátios escolares fossem obtidos, foram eleitos diferentes métodos de pesquisa com finalidade de compreender a organização espacial existente, as preferências dos usuários, as atividades realizadas nos diferentes espaços, entre outras informações relevantes.

Deste modo, na primeira aproximação foram identificadas sete escolas públicas que ofereciam Ensino Fundamental na cidade de Palmitinho/RS. Após visita e observação a estas escolas, foram escolhidas três escolas que fizeram parte deste estudo. Os critérios levados em consideração para esta seleção das escolas foram as características físicas do local, sendo que, foram levantados os usos e atividades dos pátios, tais como área de jogos, brincadeiras, quadras esportivas, playground, espaço verde.

Posteriormente, foi aplicada a combinação de diferentes instrumentos metodológicos, a saber: Revisão de Literatura, Visita Exploratória e Leitura Espacial (Walkthrough - Checklist, Ficha de inventário ambiental, Avaliação visual-, Observação e Entrevistas não estruturadas) e, por fim, observação do comportamento e impressões sobre o ambiente a partir do Mapa Comportamental, "Poema dos Desejos" e Mapa Cognitivo, sendo estes dois últimos instrumentos ressaltados neste artigo.

O "poema dos desejos" e o Mapa Cognitivo foram elaborados em folhas de tamanho A4, contendo cabeçalho com apresentação do projeto de pesquisa, local para identificação da turma e nome do respondente, itens sem obrigatoriedade de preenchimento, e mantendo a maior superfície em branco possível para o desenvolvimento do desenho/texto de cada criança.

A aplicação destes instrumentos de análise se deu com $20 \%$ dos estudantes do Ensino Fundamental $\left(1^{\circ}\right.$ a $9^{\circ}$ ano), previamente selecionados pelos professores responsáveis das turmas, tendo em vista a necessidade do preenchimento do termo de participação do aluno pelos pais. Ressalta-se que a aplicação das técnicas ocorreu em um espaço disponibilizado em ambas as instituições de ensino, durante o período das aulas, sendo os alunos liberados a partir do consentimento dos professores.
Realização:

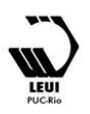




\section{$16^{\circ}$ \\ ERGODESIGN USIHC CINAHPA}

\section{Apresentação dos locais de estudo}

\subsection{Instituto Estadual de Educação 22 de maio}

O Instituto Estadual de Educação 22 de Maio está localizado no centro da cidade de Palmitinho (Figura 01), em uma área de uso misto e próxima ao acesso pela RSC - 472. Foi inaugurado em 1954 e oferece ensino a 717 alunos nas modalidades: Ensino Fundamental, Ensino Médio Politécnico, Curso Normal e Educação de Jovens e Adultos- EJA.

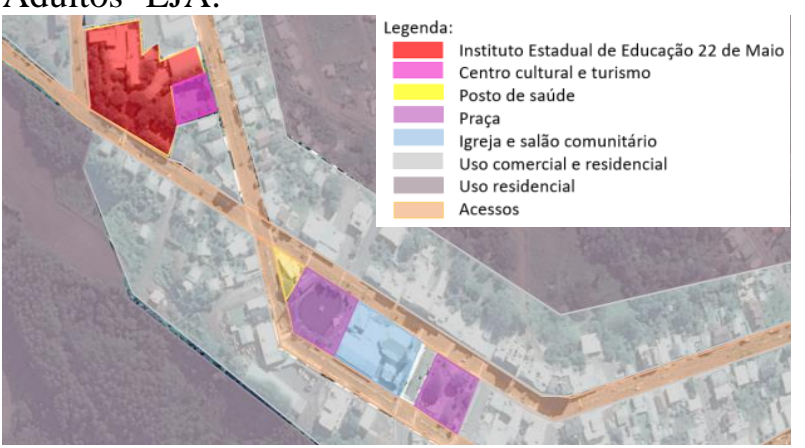

Figura 01: Implantação geral do I.E.E. 22 de Maio e entorno. Fonte: Google Earth, adaptado.

A edificação está situada em um terreno com $9.030,00 \mathrm{~m}^{2}$ e possui área construída de $3.540,00 \mathrm{~m}^{2}$. É formada por um conjunto de três pátios descobertos (Figura 02), havendo a existência de playground e um campo gramado.

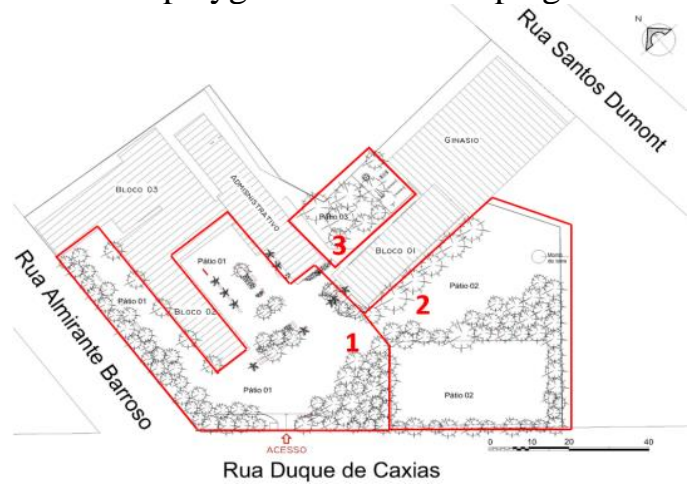

Figura 02: Planta com divisão dos pátios da I.E.E. 22 de maio. Fonte: Rech, 2016.

Com o objetivo de compreender a visão dos usuários sobre os pátios existentes, os Mapas Cognitivos e Poemas dos Desejos foram aplicados em nove turmas $\left(1^{\circ}, 2^{\circ}, 3^{\circ}, 4^{\circ}, 5^{\circ}, 6^{\circ}, 7^{\circ}, 8^{\circ}\right.$ e $9^{\circ}$ ano) do Ensino Fundamental, com $20 \%$ do total de alunos somando um total de 80 alunos. $16^{\circ}$ Ergodesign - Congresso Internacional de Ergonomia e Usabilidade de Interfaces Humano Tecnológica: Produto, Informações Ambientes Construídos e Transporte

$16^{\circ}$ USIHC - Congresso Internacional de Ergonomia e Usabilidade de Interfaces Humano Computador

CINAHPA | 2017 - Congresso Internacional de Ambientes Hipermídia para Aprendizagem.

\subsection{Escola Estadual de Ensino Fundamental Olavo Bilac}

A escola, inaugurada em 1958 com o objetivo de atender ao Ensino Fundamental, localiza-se na Linha Boa Vista, interior de Palmitinho-RS, distante $3 \mathrm{~km}$ do centro da cidade. $\mathrm{O}$ uso do solo nesta área é predominantemente residencial, com poucos serviços, incluindo mercado e uma fábrica de pré-moldados (Figuras 03).

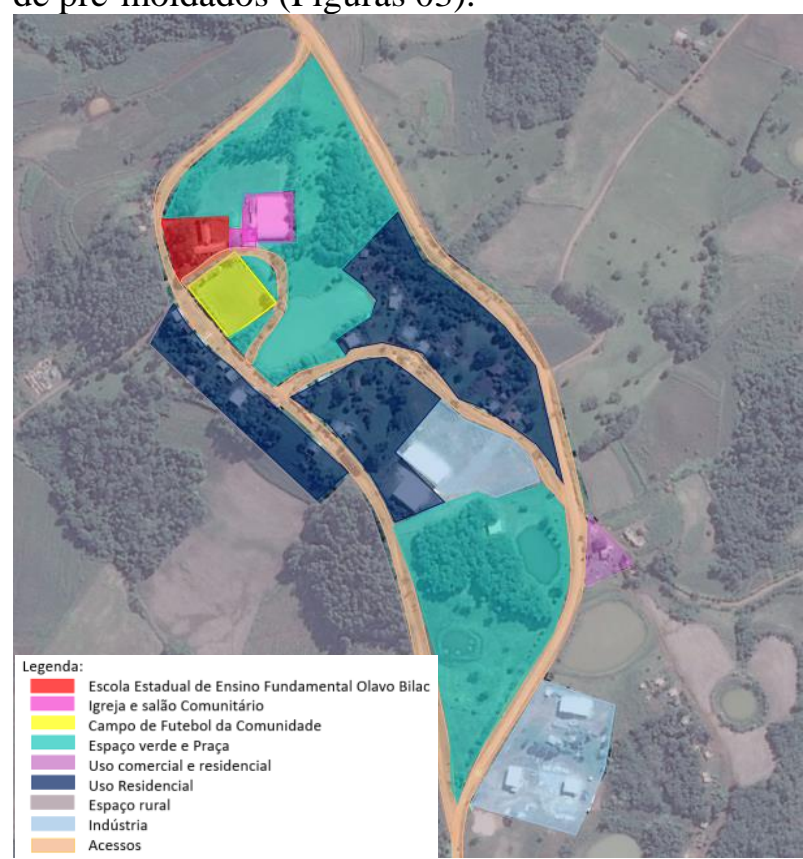

Figura 03: Implantação geral da E. E, de E. F. Olavo Bilac e entorno. Fonte: Google Earth-adaptado.

A instituição de ensino conta com 70 alunos, sendo a aplicação dos instrumentos (Mapa cognitivo e Poema dos Desejos) realizada com 20\% dos estudantes do Ensino fundamental, somando um total de 15 alunos.

Evidencia-se que, a edificação da escola está situada em um terreno com $2.551,30 \mathrm{~m}^{2}$ e possui área construída de 426,85 $\mathrm{m}^{2}$ (Figura 04). O restante do lote é ajardinado, possui um playground e espaço com vegetação de médio porte. Ao observar o lote da escola foi decidido dividi-lo em três pátios, sendo o pátio de acesso principal demarcado como pátio 01 , acesso secundário e uma grande área livre arborizada como pátio 02e o pátio 03 foi atribuído ao campo de futebol situado ao lado da escola. Apesar de não 


\section{$16^{\circ}$ \\ ERGODESIGN USIHC CINAHPA}

pertencer à escola, o campo foi incluído nas análises, por ser ambiente muito utilizado pelos alunos durante o intervalo entre aulas.

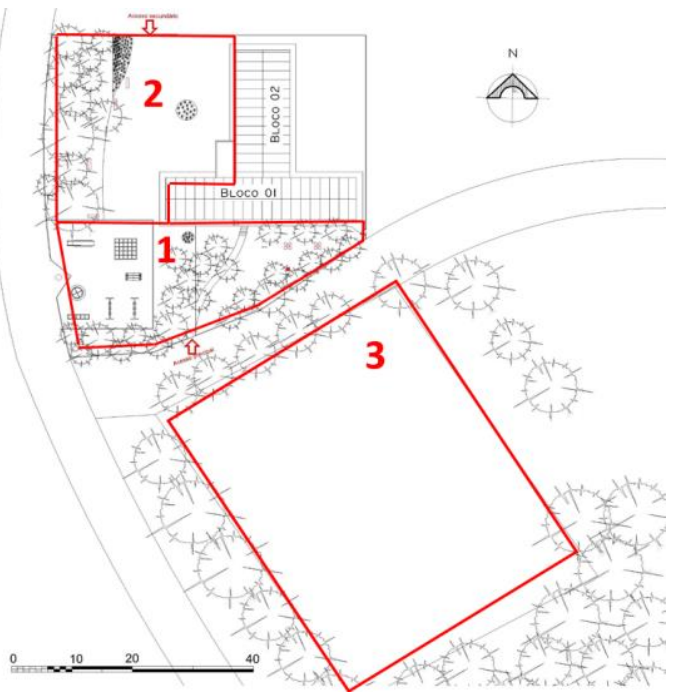

Figura 04: Planta da E.E.E.F. Olavo Bilac com divisão dos pátios. Fonte: Rech, 2016

\subsection{Escola Municipal de Ensino Fundamental Castro Alves}

A Escola Municipal de Ensino Fundamental Castro Alves teve sua inauguração no ano de 1960 e oferece ensino a 146 alunos nas modalidades: Ensino Infantil, Ensino Fundamental e Educação de Jovens e Adultos (EJA). Localiza-se na Linha Esquina do Comércio, interior de Palmitinho, esta distante $9 \mathrm{~km}$ do centro da cidade o acesso é feito pela RSC 472. O uso do solo nesta região é predominantemente residencial (Figura 05).

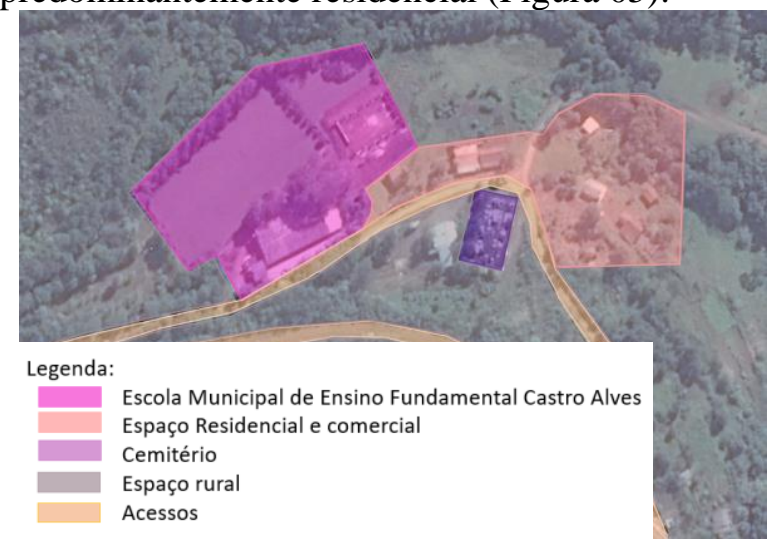

Figura 05: Implantação geral da E.M.E.F. Castro Alves e seu entorno. Fonte: Google Earth - adaptado. $16^{\circ}$ Ergodesign - Congresso Internacional de Ergonomia e Usabilidade de Interfaces Humano Tecnológica: Produto, Informações Ambientes Construídos e Transporte

$16^{\circ}$ USIHC - Congresso Internacional de Ergonomia e Usabilidade de Interfaces Humano Computador

CINAHPA | 2017 - Congresso Internacional de Ambientes Hipermídia para Aprendizagem.

A edificação da E M.E.F. Castro Alves está situada em um terreno com 7.890,00 $\mathrm{m}^{2}$ e possui área construída de $1190,00 \mathrm{~m}^{2}$. O restante do lote é ajardinado, apresentando um playground, campo de futebol e ginásio de esporte (Figura 06). Semelhante aos demais estudos de caso, os pátios também foram divididos, não sendo considerado para fim de análise o ginásio poliesportivo, devido o mesmo ser comunitário e usado ocasionalmente em dias chuvosos pela instituição de ensino.

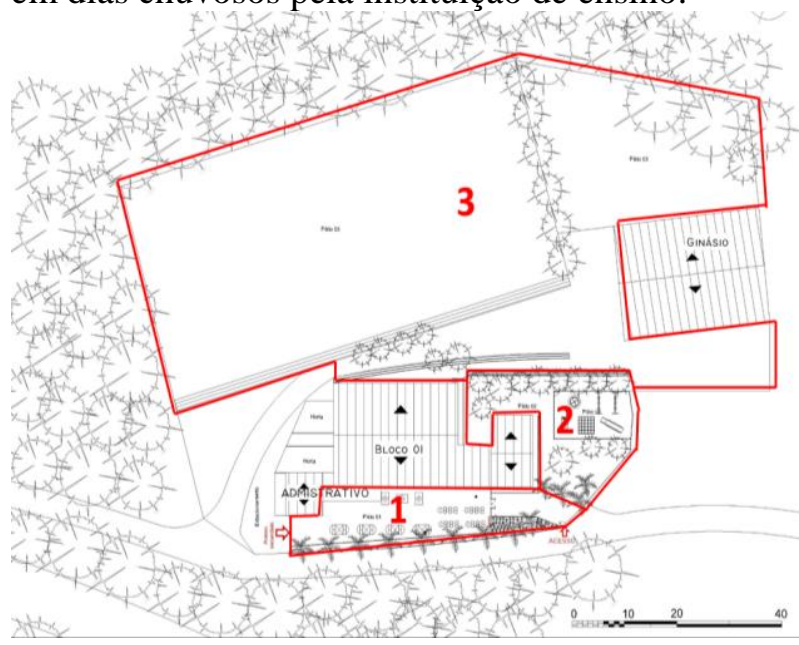

Figura 06: Planta com divisão dos pátios da E.M.E.F. Castro Alves. Fonte: Rech, 2016.

No que tange a aplicação dos instrumentos de análise (mapa cognitivo e poema dos desejos), houve a participação de um total de 25 alunos, equivalente a $20 \%$ dos alunos de Ensino Fundamental de $1^{\circ}$ a $9^{\circ}$ ano.

\section{Síntese dos resultados}

Tendo em vista que o mapa cognitivo e o poema dos desejos constituem-se em ferramentas não estruturadas, as respostas obtidas são, em muitos casos, subjetivas, o que torna mais complexo o processo de tabulação dos resultados.

Em uma primeira análise, os resultados tanto do mapa cognitivo como do poema dos desejos para cada escola foram separados por turmas, tendo em vista que para cada escola $20 \%$ dos alunos entre $1^{\circ}$ a $9^{\circ}$ ano participaram da aplicação dos instrumentos, a separação dos mesmos se deu em dois momentos: de $1^{\circ}$ a $5^{\circ}$ ano e de $6^{\circ}$ a $9^{\circ}$ ano e, em seguida, à categorização dos elementos gráficos conforme a recorrência dos desenhos/textos.
Realização:

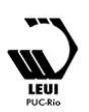




\section{$16^{\circ}$ \\ ERGODESIGN USIHC CINAHPA}

Deste modo, a fim de facilitar o ordenamento dos resultados, optou-se pela categorização das respostas em grupos, a saber: (a) Ambiente físico/infraestrutura (espaços internos, espaços externos, ginásio, campo de futebol...),

(b) Elementos concretos (brinquedos...)

(c) Elementos afetivos/ lúdicos e atividades (relação entre alunos, harmonia, brincadeiras, música...), (d) Elementos da natureza (água, animais, árvores e plantas...)., Esta divisão foi feita de modo que, a partir da tabulação dos resultados, fossem originados gráficos que facilitem a leitura e análise, traduzindo os elementos mais significativos na cognição dos usuários.

Para demonstrar os resultados do mapa cognitivo e poema dos desejos nas três escolas em estudo, optou-se pela apresentação dos resultados obtidos para cada escola a partir da aplicação de ambos os instrumentos, com os alunos de $1^{\circ}$ a $9^{\circ}$ ano (gráfico 01).

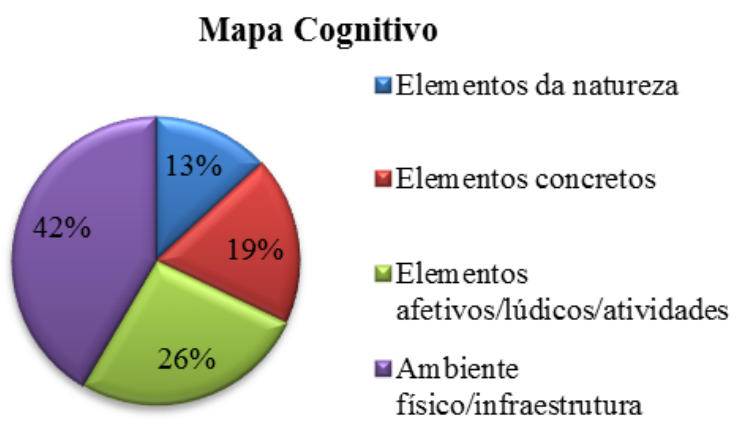

Gráfico 01: Mapa Cognitivo no I.E.E. 22 de Maio. Fonte: Autoras, 2016.

Assim no I. E.E. 22 de Maio, quando questionados referente ao modo como veem a escola, a maior parte dos alunos (42\%) abordou aspectos físicos da mesma, desenhando ou descrevendo a estrutura da edificação e o pátio (Figura 07). Em alguns momentos foram elencados aspectos da natureza juntamente à visão que possuem do pátio, a exemplo das árvores e canteiros de flores apresentados nas explanações referentes ao espaço externo. $16^{\circ}$ Ergodesign - Congresso Internacional de Ergonomia e Usabilidade de Interfaces Humano Tecnológica: Produto, Informações Ambientes Construídos e Transporte

$16^{\circ}$ USIHC - Congresso Internacional de Ergonomia e Usabilidade de Interfaces Humano Computador

CINAHPA | 2017 - Congresso Internacional de Ambientes Hipermídia para Aprendizagem.

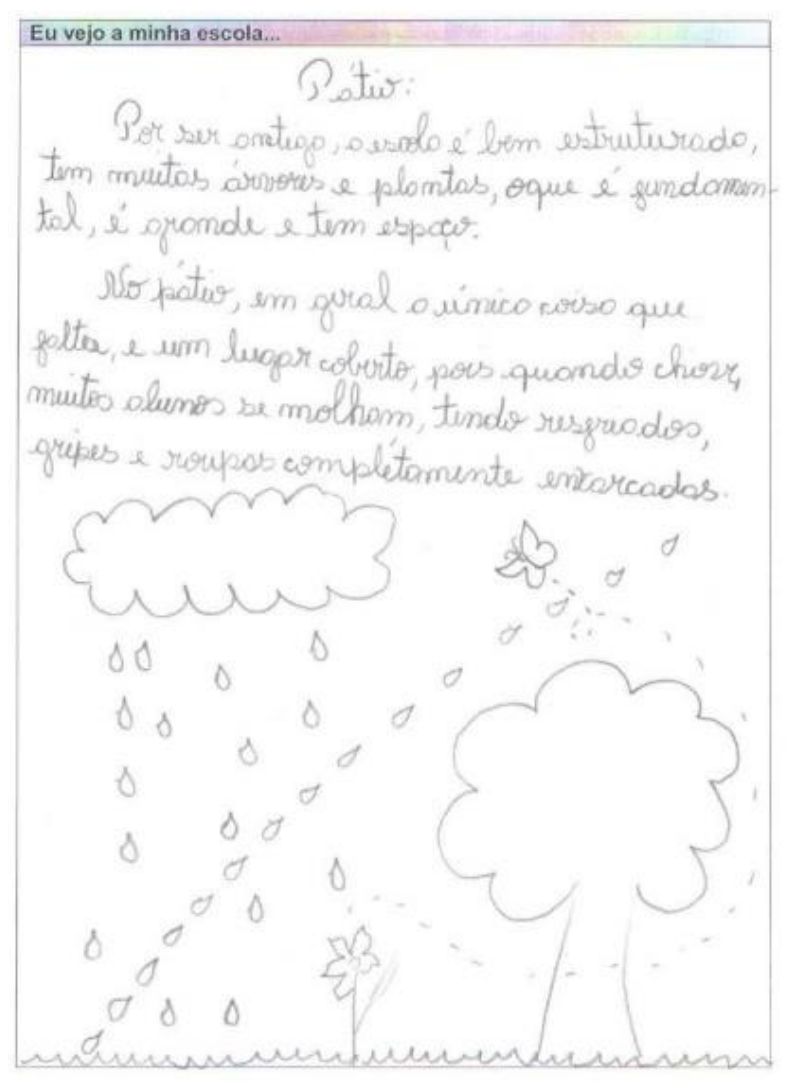

Figura 07: Exemplo de mapa cognitivo apresentado por aluno do $6^{\circ}$ ano. Fonte: dados da pesquisa, 2016.

Referente à aplicação da técnica do Poema dos Desejos, observou-se que a maioria das respostas obtidas no I.E.E. 22 de Maio estão relacionadas a elementos concretos (gráfico 02), como mobiliário e brinquedos para o playground. Bancos e lixeiras foram citados, pois, conforme opinião dos alunos constituintes da análise, estes deveriam ser distribuídas pelo pátio (Figura 08), de forma a proporcionar espaços de convivência e de aspecto limpo e agradável. Aspectos relativos à infraestrutura, como melhorias no ginásio e no campo esportivo, também foram citados durante a investigação. Os elementos na natureza, embora não tenham recebido grande destaque, foram citados em muitos momentos pelo aspecto estético, sendo que alguns alunos comentaram o interesse em flores no pátio, de forma que o mesmo ganhasse mais cores e "vida". Outro aspecto solicitado pelos alunos, em levantamento realizado, é a presença de inspetor/professor no pátio, principalmente no período de intervalo, para maior segurança e tranquilidade dos usuários. 


\section{$16^{\circ}$ \\ ERGODESIGN USIHC CINAHPA}

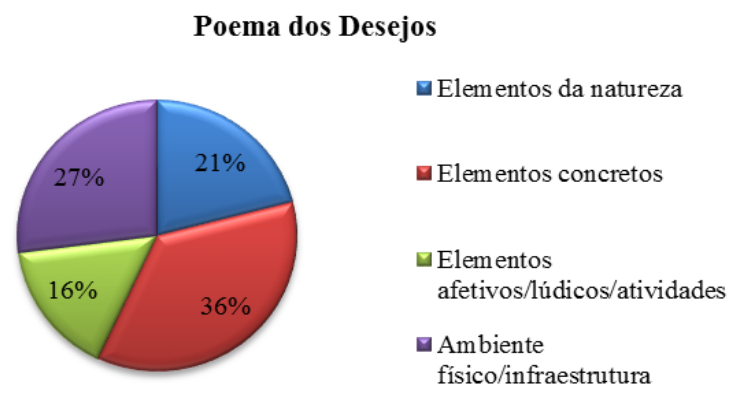

Gráfico 02: Mapa “Poema dos Desejos” I.E.E. 22 de Maio. Fonte: Autora, 2016.

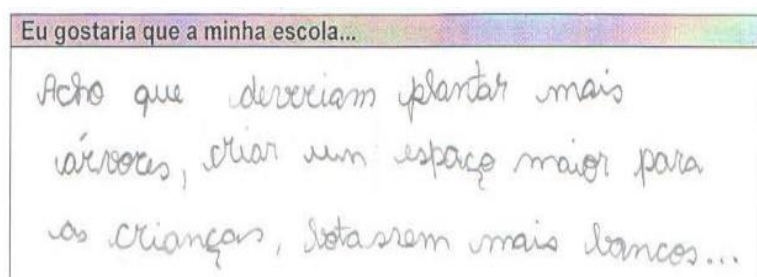

Figura 08: Poema dos desejos de aluno do $8^{\circ}$ ano.

Fonte: Dados da pesquisa, 2016.

Já na tabulação dos dados na Escola E.E.F. Castro Alves, os 15 alunos que participaram deste instrumento (20\% do total de alunos da instituição), elencaram principalmente os elementos físicos (Gráfico 03), a exemplo da edificação escolar e da cobertura existente e que foi executada recentemente (Figura 09), que une o portão de entrada ao prédio institucional. Dos elementos afetivos e atividades realizadas, destaca a boa interação e relacionamento entre alunos e educadores, bem como o uso frequente do campo comunitário para atividades de recreação.

Evidenciou-se, durante o levantamento que, muitas vezes, mais de um dos elementos adotados para fins de análise foi abordado pelos alunos envolvidos na atividade. Para realizar o levantamento de quantitativos, se contabilizou o elemento que apresentou maior destaque na resposta dada a cada técnica aplicada. $16^{\circ}$ Ergodesign - Congresso Internacional de Ergonomia e Usabilidade de Interfaces Humano Tecnológica: Produto, Informações Ambientes Construídos e Transporte

$16^{\circ}$ USIHC - Congresso Internacional de Ergonomia e Usabilidade de Interfaces Humano Computador

CINAHPA | 2017 - Congresso Internacional de Ambientes Hipermídia para Aprendizagem.

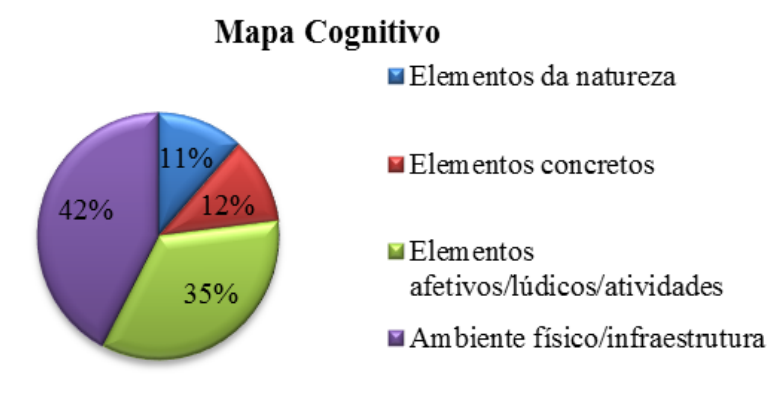

Gráfico 03: Mapa Cognitivo E.E.E.F. Olavo Bilac. Fonte: Autoras, 2016.

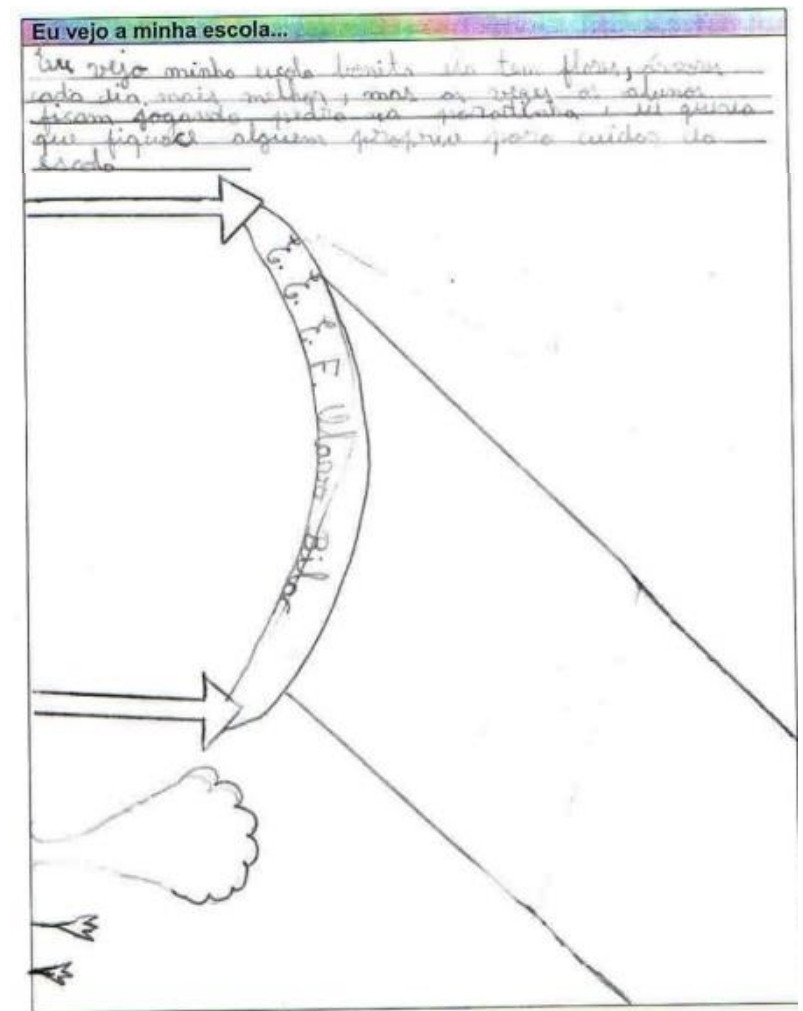

Figura 09: Resultado obtida durante aplicação do instrumento. Fonte: dados da pesquisa, 2016.

Durante a aplicação da técnica do "Poema dos Desejos", ficou evidenciado que o elemento mais considerado está relacionado ao ambiente físico e infraestrutura da escola (gráfico 04), com destaque a salas de atividades e laboratórios, e, posteriormente, de elementos concretos, relacionados principalmente à recreação (figura 10). Nesta atividade, também se verificou a abordagem de mais de um elemento por aluno, utilizados enquanto o desenvolvimento da técnica e 


\section{$16^{\circ}$ \\ ERGODESIGN USIHC CINAHPA}

para fins de análise gráfica da técnica, e considerado o elemento de maior importância destacado pelo aluno quando da realização do método.

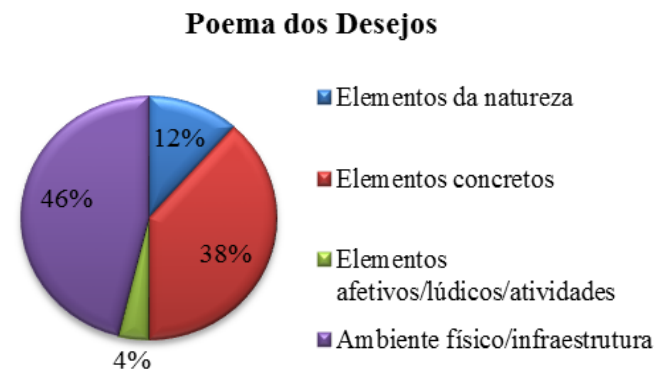

Gráfico 04: Mapa "Poema dos Desejos” E.E.E.F. Olavo Bilac. Fonte: Autoras, 2016.

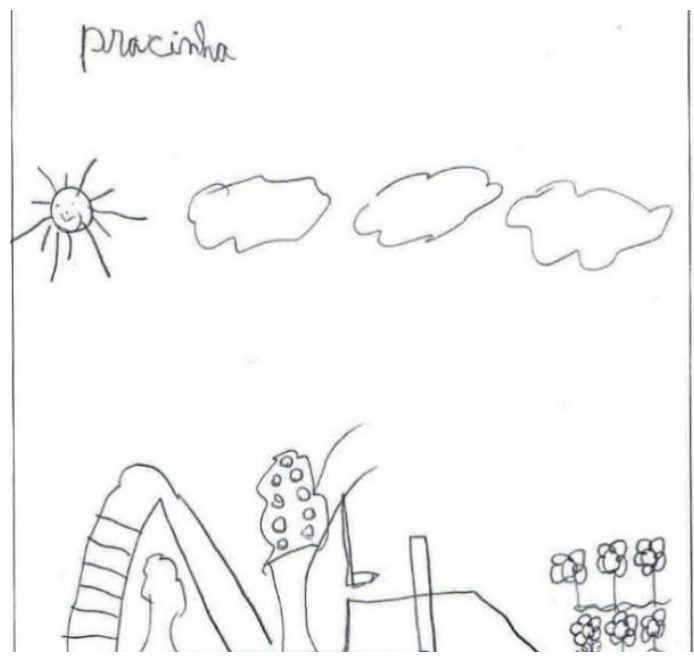

Figura 10: Poema dos desejos $2^{\circ}$ ano. Fonte: Dados da pesquisa, 2016.

Na Escola M.E.F. Castro Alves, o elemento de maior destaque foi o afetivo (gráfico 05), onde os 25 alunos que participaram quando da aplicação do instrumento revelaram grande apreço pelo ambiente educacional (elementos afetivos), frutos do bom relacionamento constatado entre alunos, professores e funcionários, revelando grande aproximação e carinho entre os mesmos (figura 11). Dentre os elementos afetivos, lúdicos e atividades, também se destacam algumas $16^{\circ}$ Ergodesign - Congresso Internacional de Ergonomia e Usabilidade de Interfaces Humano Tecnológica: Produto, Informações Ambientes Construídos e Transporte

$16^{\circ}$ USIHC - Congresso Internacional de Ergonomia e Usabilidade de Interfaces Humano Computador

CINAHPA | 2017 - Congresso Internacional de Ambientes Hipermídia para Aprendizagem.

atividades realizadas pelos mesmos como jogos de futebol e brincadeiras no pátio, como pega-pega, fortificando as trocas interpessoais.

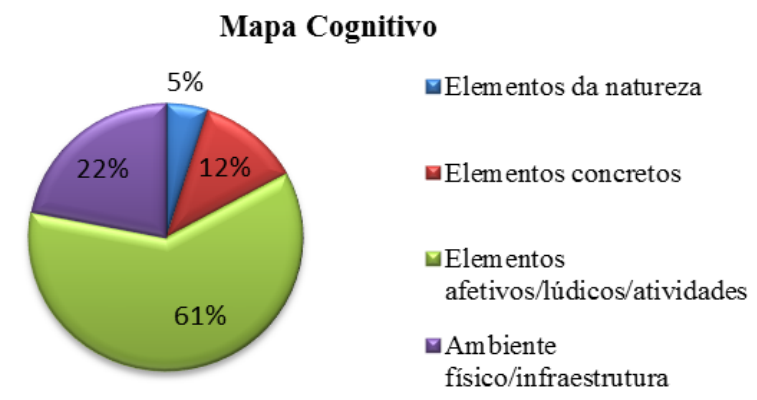

Gráfico 05: Mapa Cognitivo E.M.E.F. Castro Alves. Fonte: Autoras, 2016.

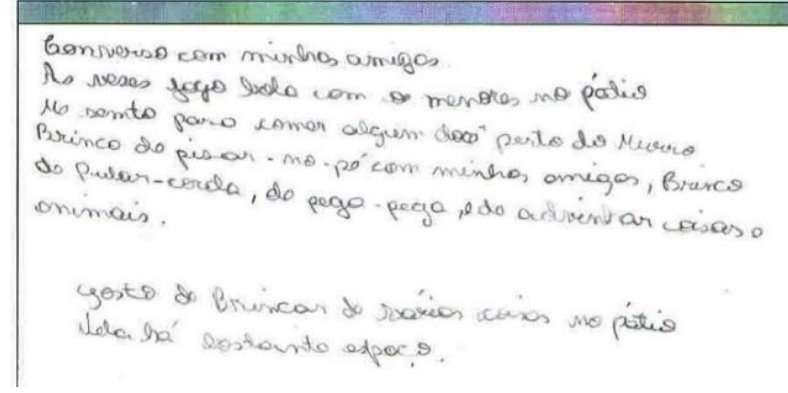

Figura 11: Apresentação de resultados obtidos. Fonte: Dados da pesquisa, 2016.

Com relação à técnica "Poema dos Desejos" na E.M.E.F. Castro Alves, a maior parte dos alunos demonstrou anseios por melhorias e investimentos na infraestrutura da escola (gráfico 06). Cita-se como exemplo a solicitação de um aumento de área do pátio calçado existente na frente da edificação escolar, em virtude de o pátio gramado não poder ser usufruído nos dias úmidos. Outro exemplo é o pedido da construção de uma piscina para aulas de natação e pista de skate, tendo em vista o apreço dos alunos por tais atividades.

No que tange aos elementos concretos, a ausência de bancos no pátio externo foi um dos principais quesitos abordados (figura 12), tendo em vista que, conforme verificado no Mapa Cognitivo, a questão de trocas interpessoais e laços afetivos foram fortemente elencadas. A presença de 


\section{$16^{\circ}$ \\ ERGODESIGN USIHC CINAHPA}

$16^{\circ}$ Ergodesign - Congresso Internacional de Ergonomia e Usabilidade de Interfaces Humano Tecnológica: Produto, Informações Ambientes Construídos e Transporte

$16^{\circ}$ USIHC - Congresso Internacional de Ergonomia e Usabilidade de Interfaces Humano Computador

CINAHPA | 2017 - Congresso Internacional de Ambientes Hipermídia para Aprendizagem. inspetor/professor no pátio para segurança e tranquilidade dos usuários também foi aspecto solicitado pelos usuários.

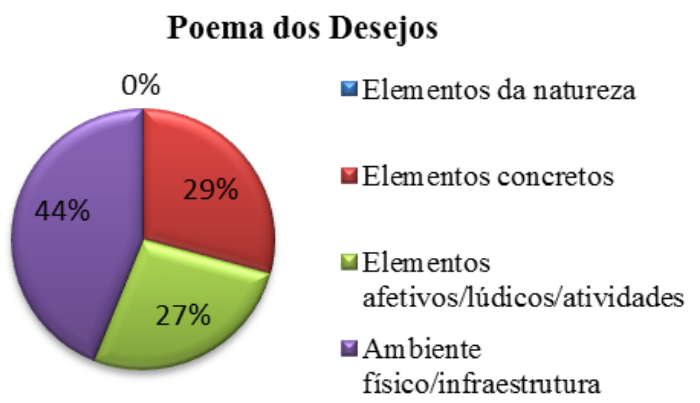

Gráfico 06: Mapa "Poema dos Desejos" E.M.E.F. Castro Alves. Fonte: Autoras, 2016.

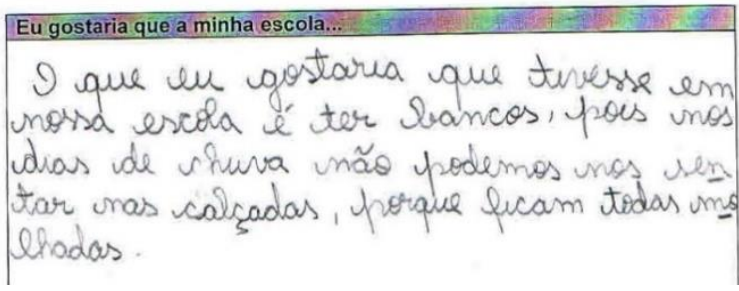

Figura 12: Poema dos Desejos $6^{\circ}$ ano. Fonte: Autora, 2016.

\subsection{Resultados análogos}

No desenvolvimento da pesquisa foram evidenciados resultados comuns entre as três instituições de ensino em análise, sendo a segurança um dos elementos de maior destaque. Sabe-se que a segurança é importante quando se trata de edifícios escolares, seja relacionada ao espaço para os alunos, diminuindo riscos de se machucarem ou causem acidentes, ou ainda à segurança do edifício escolar em relação a elementos externos à escola.

Em todos os pátios observados durante os estudos de caso, os pesquisadores observaram que a figura do inspetor era rara e até mesmo não existe em alguns casos. Desta forma, as crianças sentem que estão em um local onde não há vigilância no cumprimento de regras de comportamento, o que pode gerar ações violentas ou de vandalismo.

As áreas externas devem sempre estar equipadas com bancos para o descanso, bate-papo e pequenos agrupamentos. $\mathrm{O}$ mobiliário disponibilizado nos pátios assim como suas disposições são fatores importantes no uso do espaço.

No I. E. de E. 22 de Maio existem poucos bancos soltos em áreas com proteção da irradiação solar e com espaço adequado que permita a mobilidade das crianças, sendo um espaço com bastante apropriação pelos alunos. Porém, a E. E. Olavo Bilac possui poucos bancos, sendo estes localizados em espaço arborizado, contudo, com chão batido sem manutenção e limpeza. Já a E. M. Castro Alves não possui mobiliário, sendo um item citado frequentemente pelos alunos no levantamento realizado.

\section{Considerações finais}

Nos pátios escolares, o processo de interação entre as crianças é bastante interessante, pois assume características distintas da sala-de-aula, possibilitando aos alunos se relacionarem com outros colegas, sendo da mesma idade ou não. Desta forma, o levantamento realizado nas instituições de ensino público fundamental aqui abordado confirma a importância da participação do usuário para a obtenção de espaços arquitetônicos de qualidade.

Assim, a participação dos usuários é extremamente importante na descoberta de aspectos que somente os mesmos podem perceber, tendo em vista que estes podem não ser significativos para os pesquisadores/observadores, mas que são marcantes e repletos de significados para quem experiência aquele espaço no seu cotidiano. Da mesma forma, o pesquisador/observador contribui ao interagir com o espaço e o usuário, apontando aspectos negativos que passam despercebidos por quem está acostumado com tal espaço.

Foi constatada a importância de ouvir as crianças usuárias dos ambientes quando possível para perceber o quanto são capazes de emitirem críticas, expressando suas necessidades e sugestões criativas quanto à melhoria do ambiente construído, a exemplo do anseio pela presença de inspetor/professor no pátio, principalmente no
Realização:
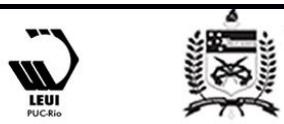
$16^{\circ}$ USIHC - Congresso Internacional de Ergonomia e Usabilidade de CINAHPA Interfaces Humano Computador

CINAHPA | 2017 - Congresso Internacional de Ambientes Hipermídia para Aprendizagem.

período de intervalo, para controle de segurança e tranquilidade dos usuários, aspecto solicitado pelos alunos em levantamento.

Desta forma, percebe-se que o método pelo qual os pátios escolares são pensados e projetados frequentemente ocorre com pouca contribuição de alunos, professores e funcionários. Também ocorre sem uma apreciação consciente da importância dos pátios escolares no desenvolvimento de crianças de todas as idades.

\section{BIBLIOGRAFIA}

AZEVEDO, Giselle A. Nielsen. Arquitetura escolar e educação: um modelo conceitual de abordagem interacionista. Tese de Doutorado. Universidade Federal do Rio de Janeiro. Rio de Janeiro. 2002.

AZEVEDO, Giselle Arteiro Nielsen; RHEINGANTZ, Paulo Afonso. TÂNGARI, Vera Regina (organizadores). O lugar do pátio escolar no sistema de espaços livres: uso, forma e apropriação. Rio de Janeiro, UFRJ/FAU/PROARQ, 2011. 203 p. (Coleção PROARQ)

BRASIL, Ministério da Educação e da Cultura. Secretaria Geral. Centro de Desenvolvimento e Apoio Técnico à Educação (CEDATE). Manual para construções escolares. Brasília:MEC/SEF, 1985.

FEDRIZZI, B. Paisagismo no pátio escolar. Porto Alegre: Editora da Universidade Federal do Rio Grande do Sul. 1999.

GONÇALVEZ, Fábio Mariz; FLORES, Laís Regina. Espaços livres em escolar: Questões para debate. In: AZEVEDO, Giselle Arteiro Nielsen; RHEINGANTZ, Paulo Afonso. 2011.

MACEDO, Silvio Soares. Prefácio. In: AZEVEDO, Giselle Arteiro Nielsen; RHEINGANTZ, Paulo Afonso. TÂNGARI, Vera Regina (organizadores). O lugar do pátio escolar no sistema de espaços livres: uso, forma e apropriação. Rio de Janeiro, UFRJ/FAU/PROARQ, 2011. 203 p. (Coleção PROARQ).
RHEINGANTZ, P. A.; AZEVEDO, G.; BRASILEIRO, A.; ALCANTARA, D.; QUEIROZ, M.. Observando a Qualidade do Lugar: procedimentos para a avaliação pós-ocupação. Rio de Janeiro: FAU-UFRJ (Coleção PROARQ), 2009.

\section{Agradecimentos}

A todos os funcionários e participantes das escolas de Ensino Fundamental onde foram realizados os estudos de casos, por colaborarem com esta pesquisa, disponibilidade e informações prestadas. 